\title{
Temporary coronary artery occlusion during off-pump coronary artery bypass grafting with the new poloxamer P407 does not cause endothelial dysfunction in epicardial coronary arteries
}

\author{
Olivier Bouchot, MD, ${ }^{a, *}$ Marie-Claude Aubin, MSc, ${ }^{\text {b,* }}$ Michel Carrier, MD, ${ }^{c}$ William E. Cohn, MD, ${ }^{d}$ \\ and Louis P. Perrault, MD, PhD ${ }^{\mathrm{b}, \mathrm{c}}$
}

From the Department of Cardiovascular Surgery, Le Bocage Hospital, ${ }^{\mathrm{a}}$ Dijon, France; the Department of Pharmacology, Université de Montréal, ${ }^{\text {b }}$ Montreal, Quebec, Canada; the Department of Surgery, Montreal Heart Institute, ${ }^{\mathrm{c}}$ Montreal, Quebec, Canada; and the Department of Surgery, ${ }^{\mathrm{d}}$ Texas Heart Institute, Houston, Tex. Financial support for this study was provided by Pluromed Inc (Woburn, Mass) for Food and Drug Administration application. The authors had full control of study design, implementation, data analysis, and manuscript preparation.

Received for publication Feb 2, 2006; revisions received April 5, 2006; accepted for publication April 24, 2006.

Address for reprints: Louis P. Perrault, MD, $\mathrm{PhD}$, Research Center, Montreal Heart Institute, 5000 Belanger St East, Montreal, Quebec H1T 1C8, Canada (E-mail: louis.perrault@icm-mhi.org).

*These authors contributed equally to the work.

J Thorac Cardiovasc Surg 2006;132:1144-9

$0022-5223 / \$ 32.00$

Copyright () 2006 by The American Association for Thoracic Surgery

doi:10.1016/j.jtcvs.2006.04.028
Objective: The aim of this study was to assess the efficacy of the novel reversible thermosensitive gel poloxamer 407 for occlusion of the coronary vessel necessary for minimally invasive operations and its effects on coronary endothelium.

Methods: Domestic swine were submitted to occlusion of the left anterior descending or right coronary artery using the poloxamer. The left and right internal thoracic arteries were used as grafts to perform coronary artery bypasses. Animals were humanely killed after 3 hours of perfusion (acute; $\mathrm{n}=8$ ) or 3 days (subacute; $\mathrm{n}=6$ ). The vascular reactivity of coronary artery was evaluated in response to serotonin and bradykinin. Histologic studies were performed to analyze cardiomyocyte necrosis and endothelial coverage.

Results: The gel led to an occlusion of $7.8 \pm 2.2$ minutes. Concentration-response curves of occluded coronary segments showed no difference of endotheliumdependent relaxations in both operated groups $(P<.05$ vs control). Histologic studies demonstrated the absence of cardiomyocyte necrosis after coronary artery occlusion in the acute group; a small infarct zone was detected in 1 animal in the subacute group, resulting from an occlusion of the first diagonal branch. The endothelial layer coverage was preserved in both groups.

Conclusion: The poloxamer 407 represents a promising technique for obtaining hemostasis at the site of anastomosis during construction of bypasses during beating heart coronary artery surgery, without damage to the endothelium or ischemic consequence.

B eating heart coronary artery surgery avoids the need for cardioplegic arrest and aortic clamping and may limit the ischemic damage to the myocardium associated with conventional cardiopulmonary bypass. ${ }^{1}$ Moreover, offpump coronary artery bypass (OPCAB) induces considerably less oxidative stress and lipid peroxidation than does on-pump bypass and offers in most cases a bloodless surgical field. ${ }^{2,3}$ Many techniques are currently used for OPCAB, including intraluminal shunts, vascular clamps, gas jet blowers, and snares, but their use may be associated with mechanical injury of the endothelium. ${ }^{4-7}$ The optimal technique to ensure hemostasis at the arteriotomy site during construction of the anastomosis remains to be developed.

The poloxamer 407 (P407; Pluromed Inc, Woburn, Mass) gel is biocompatible with cells and body fluids, nonthrombogenic, possesses low toxicity at high doses, and has weak immunogenic properties. ${ }^{8-10}$ It is soluble in aqueous solutions at low temperature and shows gelation behavior at body temperature. This reverse thermosensitive formulation has made P407 attractive for transdermal implants to 


$$
\begin{aligned}
& \text { Abbreviations and Acronyms } \\
& \begin{aligned}
\mathrm{BK} & =\text { bradykinin } \\
5-\mathrm{HT} & =5 \text {-hydroxytryptamine (serotonin) } \\
\mathrm{KCl} & =\text { potassium chloride } \\
\mathrm{LAD} & =\text { left anterior descending coronary artery } \\
\mathrm{OPCAB} & =\text { off-pump coronary artery bypass grafting } \\
\mathrm{P} 407 & =\text { poloxamer } 407 \\
\mathrm{RCA} & =\text { right coronary artery }
\end{aligned}
\end{aligned}
$$

control the delivery of various drugs ${ }^{11}$ and for temporary vascular occlusion because it solidifies only when it gets in contact with warm blood. ${ }^{12}$ The integrity of the microvascular reactivity has been evaluated after occlusion with P $407,{ }^{13}$ but its impact at the injection site in epicardial coronary arteries has not been evaluated. The objective of this study was to study the effects of P407 on endotheliumdependent vasorelaxation of epicardial coronary arteries after temporary occlusion during construction of coronary bypass grafts in a porcine model of OPCAB.

\section{Materials and Methods Anesthesia}

Twenty Landrace Yorkshire pigs of either gender, aged $8 \pm$ 1 weeks and weighing $25 \pm 4 \mathrm{~kg}$, were included in this study. Animals were maintained and tested in accordance with the recommendations of the "Guidelines on the Care and Use of Laboratory Animals" issued by the Canadian Council on Animals and the "Guidelines of Animal Care," and these practices were approved by a local animal ethics committee.

Swine were anesthetized by an intramuscular injection of a mixture of ketamine $(20 \mathrm{mg} / \mathrm{kg}$; Rogarsetic, Toronto, Ontario, Canada) and xylazine (2 mg/kg; Rompun, Cambridge, Ontario, Canada), and induction was achieved by mask ventilation with $2 \%$ isoflurane (Abbott Laboratories, Montreal, Quebec, Canada). Subsequently, the animals were intubated with a $6 \mathrm{~F}$ cuffed endotracheal tube by an orotracheal approach with a straight blade. Artificial ventilation with an oxygen/air mixture was provided throughout the surgical intervention to maintain an arterial oxygen saturation of $95 \%$, and a light anesthesia was induced by isoflurane $1 \% \mathrm{vol} / \mathrm{vol}$. Respiratory control was maintained by frequent determinations of arterial blood gases and acidosis was balanced with 8.4\% sodium bicarbonate (Abbott Laboratories, Quebec, Quebec, Canada). The electrocardiogram was recorded with 4 subcutaneous limb electrodes. Hair was shaved in the operative field and the skin was disinfected with a surgical scrub and a chlorexidine $0.5 \%$ solution. A catheter was placed in an auricular vein for administration of antibiotics at the beginning of the operation (Excenel $0.06 \mathrm{~mL} / \mathrm{kg}$; Pharmacia \& Upjohn, Orangeville, Ontario, Canada) and for intravenous fluid infusion during the operation. Arterial cannulation was performed through the right femoral artery for blood pressure analysis and a rectal probe was used for monitoring the temperature.

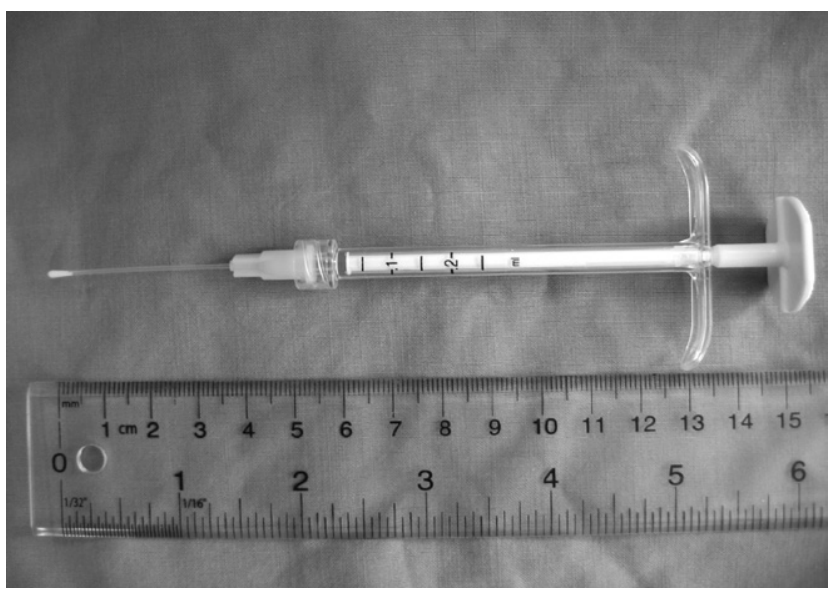

Figure 1. Cardiac control syringe used for the injection of P407 (20\% wt/vol).

\section{Surgical Technique}

After median sternotomy, the left or right internal thoracic artery was harvested as a pedicle to be used as a bypass graft to the left anterior descending (LAD) or the right coronary artery (RCA). After intravenous administration of $300 \mathrm{U} / \mathrm{kg}$ heparin (Leo Pharma, Ajax, Ontario, Canada), the pericardium was opened. The middle third of the LAD (distal to the first diagonal) or the proximal RCA was stabilized with the Octopus 4 tissue stabilizer (Medtronic, Inc, Minneapolis, Minn). After stabilization of the blood pressure, an incision $4 \mathrm{~mm}$ in length was performed on the LAD or RCA, while a light finger compression was applied $20 \mathrm{~mm}$ before the arteriotomy to avoid bleeding and to limit the gel diffusion beyond the proximal branches. P407 (20\%, $250 \mu \mathrm{L})$ was then injected with a cardiac control syringe (Pluromed Inc, Woburn, Mass) in the proximal part of the LAD or RCA. The distal part of the catheter (made of polypropylene and styrene butadiene rubber: $13.8 \mathrm{~mm}$ in length, $0.9 \mathrm{~mm}$ and $1.5 \mathrm{~mm}$ for the internal and external diameters; Pluromed) is smooth with an olivary body extremity to render it atraumatic for the endothelium (Figure 1). After introduction of the catheter $15 \mathrm{~mm}$ into the coronary artery, the gel was rapidly injected with a progressive retracted movement to avoid uneven coating of the gel, which could compromise the efficacy of the occlusion. The left internal thoracic artery was anastomosed on the LAD or the right internal thoracic artery on the RCA with a polypropylene monofilament 7-0 suture. A new injection of gel or ice to liquefy the gel was required in some experiments $(n=5$ in the acute group and $n=3$ in the subacute group).

\section{Acute Group Protocol}

Animals $(n=8)$ were humanely killed after 3 hours of reperfusion of the bypassed coronary arteries and the heart was removed to study vascular reactivity and perform histologic examination.

\section{Subacute Group Protocol}

After 3 hours of reperfusion, the chest was closed in multiple layers. An intradermal injection of an analgesic (Marcaine, 
$0.5 \mathrm{mg} / \mathrm{mL}$; Astra Zeneca, Mississauga, Ontario, Canada) and an intramuscular injection of a second analgesic (buprenorphine, $0.6 \mathrm{mg}$; Reckitt Benckiser Healthcare (UK) Limited, Solihull, United Kingdom) were given at the end of the operation, and the animals $(\mathrm{n}=12)$ were left to recover in temperature-controlled quarters. Swine received an intramuscular injection of the antibiotic ceftiofur sodium (Excenel, $0.06 \mathrm{~mL} / \mathrm{kg}$; Pharmacia \& Upjohn, Orangeville, Ontario, Canada) for the 2 following days and were given an aspirin (325 mg) daily. Animals were humanely killed by exsanguination through a median sternotomy, using the previously described anesthetic technique. The heart was removed for vascular reactivity studies and histologic examination.

\section{Coronary Harvesting}

The heart was rapidly placed in a modified Krebs-bicarbonate solution (composition in mmol/L: $\mathrm{NaCl} 118.3, \mathrm{KCl} 4.7, \mathrm{CaCl}_{2} 2.5$, $\mathrm{MgSO}_{4} 1.2, \mathrm{KH}_{2} \mathrm{PO}_{4} 1.2, \mathrm{NaHCO}_{3} 25$, ethylenediaminetetraacetic acid 0.026 , dextrose 11.1; control solution) for harvesting of coronary arteries. The LAD, the left circumflex, and right epicardial coronary arteries were dissected free from adherent fat and connective tissue and were divided into rings $4 \mathrm{~mm}$ in length.

\section{Vascular Reactivity Studies}

Rings were then placed in organ chambers filled with the Krebsbicarbonate solution $(20 \mathrm{~mL})$, maintained at $37^{\circ} \mathrm{C}$, and oxygenated with a mixture of $95 \%$ oxygen $/ 5 \%$ carbon dioxide. The rings were suspended between 2 metal stirrups, 1 connected to an isometric force transducer. Data were recorded on data acquisition software (IOS3; Emka Inc, Paris, France). After 30 minutes of stabilization, tension on rings was progressively increased to the optimal tension of its active length-tension curve (approximately $3.5 \mathrm{~g}$ ), as determined by measuring the contraction to potassium chloride $(\mathrm{KCl}$, $30 \mathrm{mmol} / \mathrm{L}$ ) at different levels of stretch. A maximal contraction was determined with $\mathrm{KCl}(60 \mathrm{mmol} / \mathrm{L})$ and the baths were then washed. Rings were excluded if they failed to contract with $\mathrm{KCl}$ (exclusion rate of less than 5\%). Afterward, all studies were performed in the presence of indomethacin $\left(10^{-5} \mathrm{~mol} / \mathrm{L}\right.$; to prevent the endogenous production of prostanoids), propranolol $\left(10^{-7} \mathrm{~mol} / \mathrm{L}\right.$; to prevent the activation of $\beta$-adrenergic receptors), and ketanserin $\left(10^{-6} \mathrm{~mol} / \mathrm{L}\right.$; incubated 45 minutes before the addition of serotonin to antagonize smooth muscle cell serotonin 5-hydroxytryptamine [5- $\left.\mathrm{HT}_{2}\right]$ receptors). After 45 minutes of stabilization, prostaglandin $\mathrm{F}_{2} \alpha$ (range $2 \times 10^{-6}$ to $10^{-5} \mathrm{~mol} / \mathrm{L}$ ) was added to achieve contraction, averaging $50 \%$ of the maximal contraction to $\mathrm{KCl}(60 \mathrm{mmol} / \mathrm{L})$.

\section{Endothelium-dependent Relaxations}

The nitric oxide-mediated relaxation pathway was studied by constructing concentration-response curves to serotonin (5-HT; $10^{-10}$ to $10^{-5} \mathrm{~mol} / \mathrm{L}$, an agonist binding to endothelial $5-\mathrm{HT}_{1 \mathrm{D}}$ receptors coupled to Gi proteins) and to bradykinin (BK; $10^{-12}$ to $10^{-6} \mathrm{~mol} / \mathrm{L}$, an agonist binding to endothelial $\mathrm{B}_{2}$ receptors coupled to $\mathrm{Gq}$ proteins leading to the release of nitric oxide and endothelium-derived hyperpolarizing factor). Since we have previously demonstrated that the 3 vessels types possess the same vascular reactivity, the left circumflex coronary artery was used as the control (data not shown).

\section{Endothelium-independent Relaxations}

Endothelium-independent relaxations were studied by the addition of a bolus of sodium nitroprusside $\left(10^{-5} \mathrm{~mol} / \mathrm{L}\right.$, an exogenous nitric oxide donor) to assess the maximal dilation.

\section{Histologic Studies}

Cardiomyocyte necrosis. Surgical biopsy specimens were taken from the anterior, posterior, and lateral free left ventricle and from the interventricular septum. They were then fixed in $10 \%$ buffered formalin, embedded in paraffin, and cut in $4-\mu$ m thick sections for histologic documentation. Each section was examined by an experienced cardiovascular pathologist blinded to the surgical procedure. Necrosis was determined using hematoxin phloxine safran.

Endothelial coverage. Segments of fresh coronary arteries were stained with silver nitrate to evaluate the endothelial cell coverage. Control and P407 rings were opened longitudinally to obtain strips $4 \times 8 \mathrm{~mm}$ in size and were pinned to the bottom of a Petri dish. Samples were first fixed for 10 minutes with $0.1 \mathrm{~mol} / \mathrm{L}$ phosphate buffer containing paraformaldehyde and glutaraldehyde. After a 1-minute wash with a sucrose solution, rings were exposed for 1 minute to $0.25 \%$ silver nitrate solution, followed by a second 1-minute wash and a second fixation period of 2 minutes. Incubation was then carried out for 3 hours in a sodium cacodylate solution under a spotlight. The stained samples were mounted whole on glass slides and the percent surface area covered by intact endothelium was then estimated by 2 blinded examiners with the aid of a microscope (magnification $\times 250$ ).

Drugs. All solutions were prepared daily; 5-HT creatinine sulfate (serotonin), BK, glutaraldehyde, indomethacin, ketanserin, paraformaldehyde. propranolol, prostaglandin $\mathrm{F}_{2 \alpha}$, silver nitrate, and sodium cacodylate were purchased from Sigma (Oakville, Ontario, Canada). Poloxamer 407 was provided by Pluromed (Lincoln, Mass).

Statistical analysis and data interpretation. Relaxations are expressed as a percentage of the maximal contraction to prostaglandin $\mathrm{F}_{2 \alpha}$ (for 5-HT) or 5-HT (for BK), presented as mean \pm standard error of the mean; $n$ refers to the number of animal used. Analysis of variance studies were performed to compare concentrationresponse curve. The Student $t$ test for paired/unpaired observations was used for the contractions.

\section{Results \\ Baseline Data}

Acute group. Of the 8 animals used in the acute group, 1 died intraoperatively of ventricular fibrillation (excluded from results) after presenting unstable hemodynamics before the anastomosis. Epinephrine was administered to restore blood pressure before the injection of P407 but led to ventricular fibrillation. Electrical cardioversion and heart massage were instituted to restore the heart rhythm but failed, leading to death. Four animals required electrical cardioversion and inotropic drug support for ventricular fibrillation episodes during coronary reperfusion. The first injection of the gel led to a successful occlusion for $8.3 \pm$ 2.1 minutes and a second injection was necessary in 4 cases. The mean volume for the first and second injections $(\mathrm{n}=5)$ 
was $190 \pm 20 \mu \mathrm{L}$ and $160 \pm 70 \mu \mathrm{L}$, respectively, totalizing $300 \pm 110 \mu \mathrm{L}$. The mean anastomosis time with the gel was $11.3 \pm 1.8$ minutes.

Subacute group. Six of 12 animals used in the subacute group died. In 4 cases, death was due to occlusion of the first diagonal branch during performance of the anastomosis. One animal died after having unstable hemodynamics before the beginning of surgery and 1 died of arrhythmia during the reperfusion. These pigs were thus excluded from data analysis. The occlusion time for the first injection was $7.2 \pm 2.4$ minutes and the dosage was $200 \mu \mathrm{L}$. A second injection was needed 3 times, and the quantity used was $130 \pm 60 \mu \mathrm{L}$. The total dose was $380 \pm 350 \mu \mathrm{L}$. The anastomosis time was $11.3 \pm 2.7$ minutes.

\section{Vascular Reactivity Studies}

Contractions. The amplitude of the contractions to $\mathrm{KCl}$, to prostaglandin $\mathrm{F}_{2} \alpha$, and to the concentration of prostaglandin $\mathrm{F}_{2} \alpha$ needed to achieve the target level of contraction to $\mathrm{KCl}$ were not statistically different between control and P407 epicardial coronary artery rings in both the acute and the subacute groups (Table 1).

Endothelium-dependent relaxations. Concentrationresponse curves to 5-HT and BK of arteries occluded with P407 (LAD and RCA rings) in both groups showed no statistically significant difference compared with the left circumflex artery control rings $(P<.05$ for both agonists), confirming the absence of alterations in endotheliumdependent relaxations (Figures 2 and 3).

Endothelium-dependent relaxations. Relaxation reached $100 \%$ after the bolus of sodium nitroprusside in both the acute and subacute groups (data not shown).

\section{Histologic Studies}

Cardiomyocyte necrosis. In the myocardium vascularized by the LAD or RCA occluded with P407, there was no necrosis zone in the acute group. In the subacute group, a necrosis zone in the right ventricle was limited to the

TABLE 1. Contraction to $\mathrm{KCl}(60 \mathrm{mmol} / \mathrm{L})$ and prostaglan$\operatorname{din} F_{2 \alpha}$

\begin{tabular}{lcccc}
\hline Agonist & $\begin{array}{c}\text { Control } \\
(\mathbf{n}=\mathbf{1 5})\end{array}$ & $\begin{array}{c}\text { Acute } \\
(\mathbf{n}=\mathbf{1 2})\end{array}$ & $\begin{array}{c}\text { Subacute } \\
(\mathbf{n}=\mathbf{1 1})\end{array}$ & $\boldsymbol{P}$ \\
\hline & & & & \\
$\mathrm{KCl} 60 \mathrm{mmol} / \mathrm{L}(g)$ & $7.9 \pm 0.8$ & $8.8 \pm 1.1$ & $8.3 \pm 1.1$ & $\mathrm{NS}$ \\
$\mathrm{PG}(g)$ & $5.1 \pm 0.6$ & $5.6 \pm 0.6$ & $4.8 \pm 0.6$ & $\mathrm{NS}$ \\
$\begin{array}{l}\text { Dosage of PG } \\
\quad\left(10^{-6} \mathrm{~mol} / \mathrm{L}\right)\end{array}$ & $3.2 \pm 0.5$ & $3.2 \pm 0.6$ & $3.2 \pm 0.6$ & $\mathrm{NS}$ \\
Ratio PG/KCl (\%) & $67.0 \pm 6.8$ & $68.4 \pm 5.9$ & $59.6 \pm 7.3$ & $\mathrm{NS}$
\end{tabular}

$\mathrm{n}$ represents the number of rings used. $K C l$, Potassium chloride; $P G$, prostaglandin $\mathrm{F}_{2 \alpha} ; N S$, not significant. Data are presented as mean \pm standard deviation.

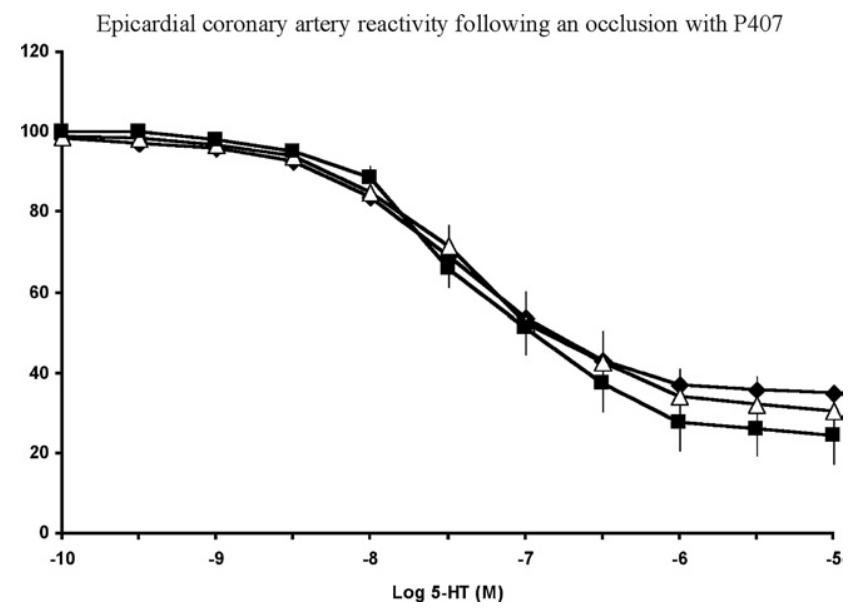

Figure 2. Cumulative concentration-response curves to serotonin (5-HT) in rings of porcine coronary arteries occluded with P407 from the acute group $(\triangleleft)$, the subacute group $(\square)$ and controls $(\triangle)$. Responses are expressed as the percent of relaxation to the contraction induced by prostaglandin $\mathrm{F}_{2} \alpha$. Results are presented as the mean \pm standard deviation.

collateral ligature at the site of the anastomosis $(1.5 \times$ $1.8 \mathrm{~cm})$ and to a zone in the left ventricle $(4 \times 3 \mathrm{~cm})$; the latter remains unexplained because no atherothrombosis was found in the infarcted zone. Contraction bands were present in hearts from both groups, resulting from electrical cardioversion.

Epicardial coronary artery reactivity following an occlusion with P407

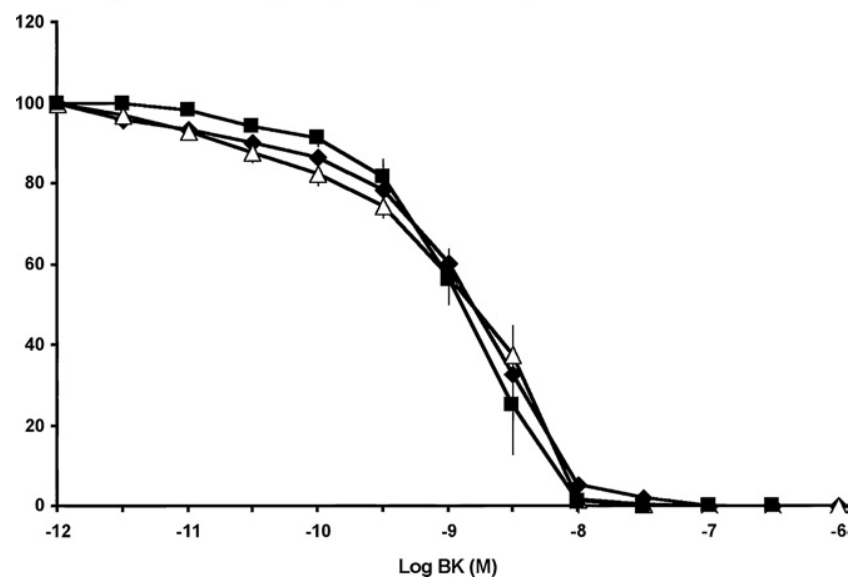

Figure 3. Cumulative concentration-response curves to bradykinin (BK) in rings of porcine coronary arteries occluded with P407 $(\diamond)$, the subacute group $(\square)$ and controls $(\triangle)$. Responses are expressed as the percent of relaxation to the contraction induced by serotonin. Results are presented as the mean \pm standard deviation. 
Endothelial coverage. P407-occluded vessels from both groups were compared with control strips. Histologic study of the endothelial cell coverage demonstrated preservation of the endothelial layer in P407 strips (100\% of controls) (Figure 4).

\section{Discussion}

The major findings of the present study are as follows: injection of P407 (1) creates a successful occlusion of epicardial coronary arteries during $\mathrm{OPCAB}$ and (2) causes no significant decrease in endothelium-dependent relaxations mediated by the Gi- and Gq-protein pathways. The necessity of a bloodless field to obtain optimal visibility during performance of the anastomosis is an issue of concern in OPCAB. The most widely used variant of OPCAB involves use of sutures or silicone rubber tapes (Silastic; Dow Corning Corporation, Midland, Mich) to snare the coronary artery extravascularly, upstream and downstream from the anastomotic site on the target artery. However, examination with scanning electron microscopy showed that snares cause focal endothelial denudation and atherosclerotic plaque rupture. ${ }^{14}$ Furthermore, these occlusive systems do not allow distal coronary perfusion. Intracoronary shunts used as hemostatic devices in OPCAB also have the advantage of allowing myocardial protection by maintaining distal coronary perfusion. However, shunts cause a severe endothelial dysfunction ${ }^{15}$ due to rubbing of the endothelial layer during the positioning and the removal of the devices. ${ }^{16}$ In fact, shunting to obtain total hemostasis at the anastomotic site and a satisfactory intracoronary flow to perform anastomosis under optimal conditions requires a slightly oversized shunt, but an oversized shunt is associated with severe endothelial dysfunction and intimal lesions. ${ }^{17}$

The polymer solution is injected as a soft gel at room temperature $\left(\sim 20^{\circ} \mathrm{C}\right)$ into the arteriotomy, and the rise in temperature leads to a stiff gel. The gel will start to dissolve in blood, and when the concentration of the polymer decreases below approximately $12.5 \mathrm{w} \%$, it turns back into a liquid and quickly dilutes in blood to a concentration at which it cannot turn back into a gel at physiologic temperatures. Alternatively, cooling of the gel with ice or cold saline does liquefy the gel as the temperature falls below the gelation point. As a liquid, it quickly dilutes in blood and again there is no possibility for it to turn back into a gel at physiologic temperatures. P407 is not metabolized and is excreted renally with a half-life of approximately 25 hours.

The current study shows that the hemostatic technique involving intracoronary P407 to achieve a clear operative field does not cause endothelial dysfunction, demonstrated by the preservation of the epicardial coronary artery endotheliumdependent relaxations. This is supported by the absence of significant alterations of endothelial cell signaling pathway involving the Gi protein-mediated relaxations, as demon-

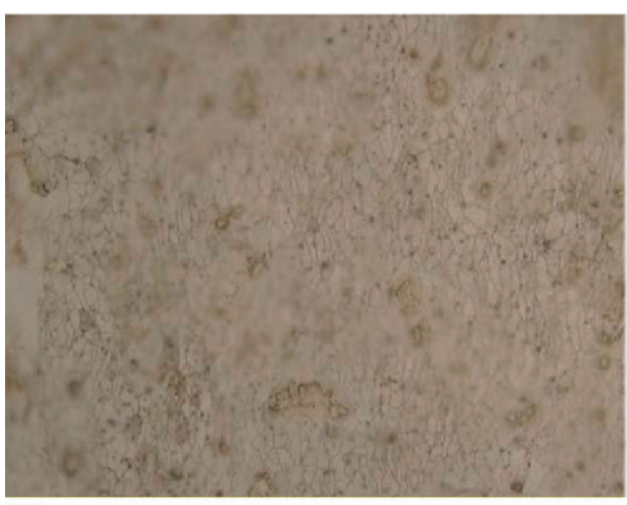

(A)

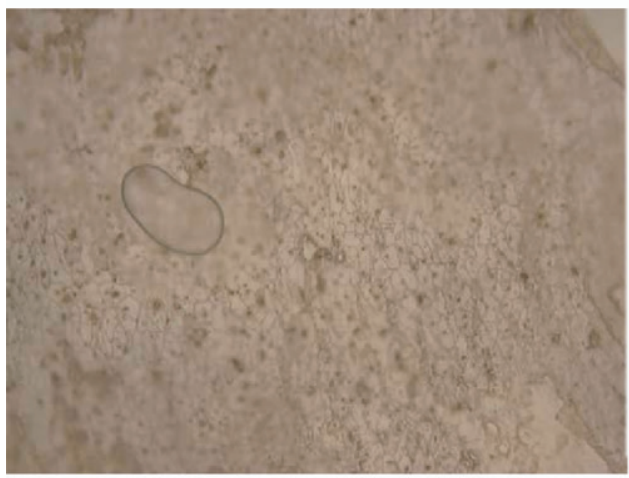

(B)

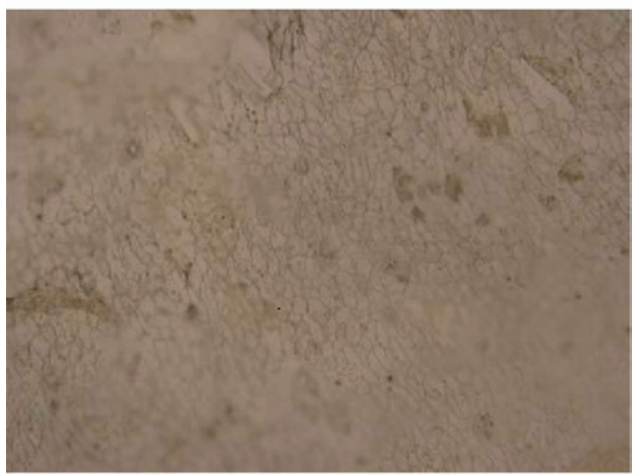

(C)

Figure 4. Representative photomicrograph (magnification $\times 250$ ) of silver nitrate staining showing preservation of the endothelial layer of control strips (A), strips occluded with P407 in the acute group (100\% of controls) (B), and strips occluded with P407 in the subacute group (100\% of controls) (C).

strated by concentration-response curves to 5-HT, and the Gq protein-mediated pathway, as demonstrated by concentrationresponse curves to $\mathrm{BK}$.

Boodhwani and colleagues ${ }^{13}$ have demonstrated that temporary occlusion of the LAD with P407 does not cause abnormalities in coronary flow during reperfusion, does not 
adversely affect regional myocardial function, and has no effect on endothelium-independent microvessel relaxation. Endothelium-dependent relaxation to adenosine diphosphate is preserved whereas response to substance $\mathrm{P}$ is mildly impaired, perhaps because of a local effect of the gel. ${ }^{13} \mathrm{In}$ addition to coronary anastomosis, P407 effectively occluded renal and pulmonary arteries subjected to glue embolization. ${ }^{9}$ This study demonstrates that this agent has the potential to be used to protect a territory during polymer, particulate, or chemo-embolizations.

\section{Limitations}

The present results validate the efficacy and safety of P407 on the beating heart for minimally invasive coronary artery bypass grafting in the acute impact on endothelial function per se in healthy blood vessels. Obviously, caution must be used when extrapolating this conclusion to atherosclerotic vessels, which may have a lesser tolerance to both operative manipulation and ischemia-reperfusion. ${ }^{18}$ On the other hand, in chronically occluded vessels with a large collateral blood flow and generous retrograde perfusion, back bleeding at the anastomotic site may be controlled imperfectly but tolerance to temporary occlusion may be greater.

In conclusion, the novel reversible thermosensitive gel P407 is safe and efficacious for temporary occlusion of the coronary vessel necessary for minimally invasive coronary artery operations. No negative effects were demonstrated on coronary endothelial function, as assessed by the preservation of the endothelial coverage and of endothelium-dependent relaxations.

We thank Marie-Pierre Mathieu and Émilie Reny-Nolin for their technical assistance, and Karine Tétrault for statistical analysis.

\section{References}

1. Borst C, Santamore WP, Smedira NG, Bredee JJ. Minimally invasive coronary artery bypass grafting: on the beating heart and via limited access. Ann Thorac Surg. 1997;63:S1-5.
2. Matata BM, Soshowski AW, Galinanes M. Off pump bypass graft operation significantly reduces oxidative stress and inflammation. Ann Thorac Surg. 2000;69:785-91.

3. Wildhirst SM, Schulze C, Conrad N, Sreejayan N, Reichenspurner H, von Ritter C, et al. Reduced myocardial cellular damage and lipid peroxidation in off-pump versus conventional coronary artery bypass grafting. Eur J Med Res. 2000;5:222-8.

4. Wippermann J, Albes JM, Brandes H, Kosmehl H, Bruhin R, Wahlers T. Acute effects of tourniquet occlusion and intraluminal shunts in beating heart surgery. Eur J Cardiothorac Surg. 2003;24:757-61.

5. Fonger JD, Yang XM, Cohen RA, Haudenschild CC, Shemin RJ. Human mammary artery endothelium sparing with fibrous jaw clamping. Ann Thorac Surg. 1995;60:351-5.

6. Perrault LP, Menasché P, Wassef M, Bidouard JP, Janiak P, Villeneuve N, et al. Endothelial effects of hemostatic devices for continuous cardioplegia or minimally invasive operations. Ann Thorac Surg. 1996;62:1158-63.

7. Perrault LP, Nickner C, Desjardins N, Carrier M. Effects on coronary endothelial function of the Cohn stabilizer for beating heart bypass operations. Ann Thorac Surg. 2000;70:1111-4.

8. Park H, Park, K. Biocompatibility issues of implantable drug delivery. Pharm Res. 1996;13:1770-6.

9. Raymond J, Metcalfe A, Salazkin I, Schwarz A. Temporary vascular occlusion with poloxamer 407. Biomaterials. 2004;25:3983-9.

10. Ricci EJ, Lunardi LO, Nanclares DMA, Marchetti JM. Sustained release of lidocaine from Poloxamer 407 gels. Int J Pharm. 2005;288: 235-44.

11. Craig DQM. Pharmaceutical material science-resuscitation or reincarnation? J Pharm Pharmacol. 1996;46:119-26.

12. Qui Y, Park, K. Environment-sensitive hydrogels for drug delivery. Adv Drug Deliv Rev. 2001;53:321-9.

13. Boodhwani M, Cohn WE, Feng J, Mieno S, Ramlawi B, Schwarz A, et al. Safety and efficacy of a novel gel for vascular occlusion in off-pump surgery. Ann Thorac Surg. 2005;80:2333-7.

14. Hangler HB, Pfaller K, Antretter H, Dapunt OE, Bonatti JO. Coronary endothelial injury after local occlusion on the human beating heart. Ann Thorac Surg. 2001;71:122-7.

15. Chavanon O, Perrault LP, Menasché P, Carrier M, Vanhoutte PM. Endothelial effects of hemostatic devices for continuous cardioplégie or minimally invasive operation. Ann Thorac Surg. 1999;68: 1118-20.

16. Vanhoutte PM, Shimokawa H. Endothelium-derived relaxing factor and coronary vasospasm. Circulation. 1989;80:1-9.

17. Demaria R, Fortier S, Malo O, Carrier M, Perrault LP. Influence of intracoronary shunt size on coronary endothelial function during offpump coronary artery bypass. Heart Surg Forum. 2003;6:72-6.

18. Amrani M, Chester AH, Jayakumar J, Yacoub MH. Aging reduces postischemic recovery of coronary endothelial function. J Thorac Cardiovasc Surg. 1996;111:238-45. 